\title{
Didáctica en la enseñanza de la Biología Celular en estudiantes preuniversitarios
}

Didactics in the teaching of Cellular Biology in pre-university students

Didática no ensino de Biologia Celular em pré-universitários

\section{ARTÍCULO GENERAL}

\section{Edison Renan Quispe Ramos}

edishon22@gmail.com

https://orcid.org/0000-0002-6857-9579

Investigador Independiente, Lima -Perú

Recibido 10 de Enero 2020 | Arbitrado y aceptado 06 de Febrero 2021 | Publicado el 01 de Abril 2021

\section{RESUMEN}

La presencia de las ciencias naturales en la cotidianidad es cada vez más profunda, representando conocimientos cuyo valor social se ha incrementado y por ende, es trascendental que aquellos que estudien estos temas se inculquen también para una aplicación ya no solo en el plano teórico sino también práctico. Así, es determinante el rol de la didáctica y las estrategias derivadas de esta, para que aquellos individuos en un proceso de enseñanza-aprendizaje, sobre todo los que están por atravesar un periodo como la decisión de seguir una carrera universitaria en dicha materia, se convenzan de que los conocimientos que se les impartan tienen utilidad, promueven su capacidad analítica, y crítica, y que tendrán habilidades que guardan estrecha relación con las exigencias del mundo actual.

\section{ABSTRACT}

The presence of the natural sciences in everyday life is becoming deeper, representing knowledge whose social value has increased and therefore, it is transcendental that those who study these issues are also inculcated for an application, not only theoretically but also practical. Thus, the role of didactics and the strategies derived from it are decisive, so that those individuals in a teaching-learning process, especially those who are about to go through a period such as the decision to pursue a university degree in said subject, Convince them that the knowledge imparted to them is useful, promotes their analytical and critical capacity, and that they will have skills that are closely related to the demands of today's world.

\section{RESUMO}

A presença das ciências naturais no quotidiano é cada vez mais profunda, representando conhecimentos cujo valor social tem aumentado e por isso, é transcendental que aqueles que estudam estas temáticas também sejam inculcados para uma aplicação, não só teórica mas também prática. Assim, o papel da didática e as estratégias dela derivadas são decisivos, para que aqueles indivíduos em um processo de ensinoaprendizagem, especialmente aqueles que estão prestes a passar por um momento como o da decisão de cursar uma graduação na referida disciplina, convençam que os conhecimentos que lhes são transmitidos são úteis, promovem a sua capacidade analítica e crítica e que terão competências estreitamente relacionadas com as exigências do mundo de hoje. 


\section{Introducción}

El siglo XXI está caracterizado por una revolución sociocultural, que tiene como fundamento el desarrollo de la ciencia así como el impacto social de sus aplicaciones prácticas. A nivel educativo, esto supone que el proceso de enseñanza - aprendizaje de las ciencias sea también una actividad sociocultural de vital importancia por lo que debe revelar su utilidad práctica e impacto en la sociedad así como estar constantemente actualizándose (Basulto et al. 2020).

Las ciencias naturales constituyen un área elemental de la programación de contenidos de los niveles educativos tanto en primaria como en los estudios superiores, no obstante, muchas veces el contenido de estas áreas se torna abstracto y complejo, generando retos y desafíos muy grandes para los docentes que enseñan tales disciplinas (Lucumí, 2015) por lo que se ven en la necesidad de aplicar estrategias didácticas e innovadoras para, precisamente, actualizarse y reformular la labor los docentes y de los estudiantes en los procesos de enseñanza y aprendizaje y reorientar estos para que estén acordes a la realidad presente.

En ese sentido, son las Tecnologías de la Información y Comunicación (TIC), el Internet y los diversos recursos audiovisuales algunos elementos que han provocado modificaciones en las formas de aprendizaje. Cabe destacar que la aparición de estos dispositivos y aplicaciones ha permitido facilitar una mejor comprensión de conceptos complejos que surgen en la preparación hacia la educación superior, como los relacionados a la ciencia y específicamente a la Biología Celular (Gómez et al, 2019) y por ende, dicha diversidad de formatos disponibles hace posible que se cuente con una enorme amplitud de estrategias por aplicar.

Las estrategias didácticas suponen efectos positivos sobre el interés y motivación del estudiante para aprender significativamente, así como también influyen en que estudiantes y docentes se aproximen al conocimiento de las ciencias naturales como un científico natural (Prieto y Sánchez, 2019).

Por todo ello, es preciso exponer los beneficios de la didáctica en el proceso de enseñanza-aprendizaje de conocimientos de las ciencias naturales sobre todo los conceptos que se derivan de la biología celular. 


\section{Metodología}

La búsqueda de la información para la revisión de literatura se hizo tras consultar las siguientes bases de datos como son Proquest, Scopus y Google Scholar para encontrar revistas del más alto nivel científico. Asimismo, cabe mencionar que para la realización de lo mencionado se emplearon también palabras clave como como: Didáctica, Didáctica de la enseñanza, Biología Celular, Enseñanza de la biología celular.

Cada uno de estos descriptores se combinaron entre sí durante la búsqueda utilizando los operadores boléanos “and” y “or”. Además, algunos de los criterios o filtros que se utilizaron para hacer muchos más específica la búsqueda y ser más precisos con los documentos encontrados en las diferentes bases de datos consultadas fueron: que sean artículos de revistas, de Q1 y Q2, enfocados en nivel de institución educativa (preuniversitaria) y la antigüedad de la publicación que no sea mayor a cinco años.

Toda la información previa relacionada a los filtros aplicados y las especificaciones sirvieron como criterios de inclusión, es decir que sean artículos publicados en revistas científicas, que no excedan los cinco años de antigüedad, que la temática guarde relación con las variables de didáctica de la enseñanza y biología celular. Se excluyeron, en tanto, todos los documentos que no respetaran lo postulado así como aquellos que estaban incompletos o que tenían enlaces averiados.

\section{Desarrollo de resultados y Discusión}

\section{Proceso de enseñanza-aprendizaje}

Según Abreu et al. (2018) el proceso de enseñanza-aprendizaje constituye una unidad cuyo objetivo es contribuir a la formación integral del futuro profesional. Este procedimiento lo dirige el docente, para favorecer el aprendizaje de saberes varios, como son conocimiento, valores y habilidades.

Asimismo, Pérez (2019) respalda lo dicho en el párrafo anterior y enfatiza que la enseñanza-aprendizaje se conforma de la personalidad del estudiante debido a que es en él que nacerá la relación entre lo cognitivo y lo afectivo; siendo esta última la razón por la que se considera un proceso de carácter pedagógico. 
A continuación se exponen las principales teorías vinculadas al proceso de enseñanza y el aprendizaje de las ciencias según Villaruel (2015):

\section{Aprendizaje por transmisión-recepción}

Comúnmente se afirma que el aprendizaje por recepción verbal es el método más eficaz para transmitir los contenidos de una materia. Sin embargo, se sabe de antemano que la enseñanza expositiva es autoritaria y vertical, obligando a los estudiantes a reconocer los contenidos, explicita o tácitamente, como dogmas.

\section{Aprendizaje por descubrimiento}

El aprendizaje por descubrimiento es una alternativa a los métodos basados en la memorización y en la rutina de trabajo, al poner su énfasis en la participación activa de los estudiantes a partir de un proceso gradual pero sostenido de aprendizaje y en la aplicación de los fundamentos teóricos de la ciencia recreados en sus procesos.

El instructor presenta al estudiante todas las herramientas necesarias para que pueda inmiscuirse en el proceso de descubrimiento, lo que se espera logre por sí mismo mientras selecciona lo que desea aprender. Cuando todo se lleva a cabo de manera adecuada, asegura un conocimiento significativo y fomenta en los estudiantes hábitos intelectuales de investigación y rigor metodológico en sus intervenciones.

\section{Aprendizaje Significativo}

Es entendido como el proceso mediante el cual se relaciona un nuevo conocimiento o información con la estructura cognitiva del aprendiz; ello debe darse de forma coordinada (no arbitraria) y sustantiva (no literal). Se trata de una nueva visión de la tradicional enseñanza expositiva y del aprendizaje por recepción gracias a que recupera también los saberes previos de los estudiantes (esquemas previos), sustrato que permite un nuevo aprendizaje de conceptos, los mismos que deben estar adecuadamente estructurados por parte del maestro (pieza clave del proceso, quien define actividades que llevan a su comprensión, asimilación y reforzamiento).

Cabe mencionar que más allá de las teorías desde las que se parta el proceso de enseñanza-aprendizaje, este siempre estará plasmado en el acto didáctico, concebido 
como un acto esencialmente comunicativo, de intercambio bidireccional entre docente y discente en un escenario social de enseñanza (Gómez et al. 2016).

Figura 1. Proceso del acto didáctico

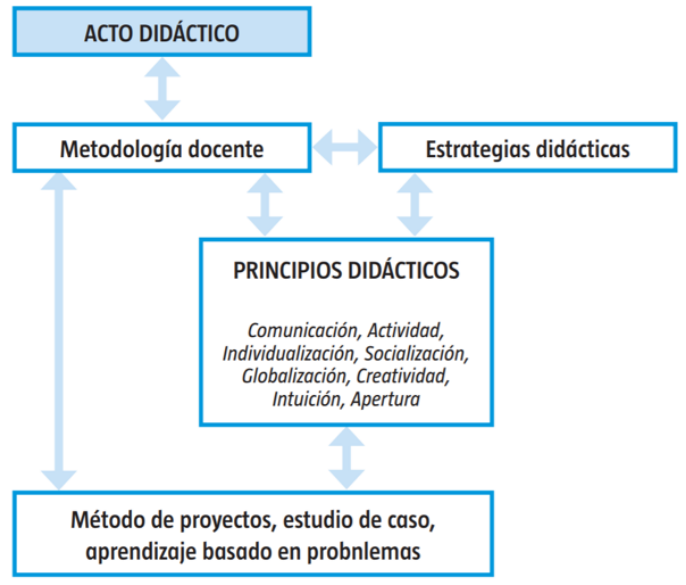

Fuente: (Gómez et al. 2016).

En ese sentido, cabe mencionar qué es la didáctica, cómo se relaciona esta disciplina con la enseñanza, y cómo, a su vez, se relacionan con las ciencias naturales y la biología celular. Asimismo, es preciso reconocer a los elementos que conforma el acto didáctico, el mismo que se muestra en la Figura 1.

\section{Didáctica}

Si se parte de una de las definiciones más antiguas, la didáctica es definida por el Comenio en el Siglo XVII, en su obra Didáctica Magna, como aquel artificio universal que sirve para enseñar todas las cosas a todos, con rapidez, alegría y eficacia; este concepto está estrechamente asociado a su origen etimológico Didaskein, que significa enseñar y Tecne que significa arte (Prieto y Sánchez, 2019).

La didáctica, para Gómez et al (2016) se relaciona entonces con el arte de enseñar, evoca al artista y a su creación, al didacta y a su proceso de enseñar. El didacta, desde esta metáfora, es el artista que crea un escenario fecundo para el enseñar y el aprender, tiene una habilidad propia que manifiesta en el acto de enseñar.

Por ende, se entiende que la didáctica es una disciplina pedagógica aplicada fundamental en la formación del profesorado al asumir como objeto central el estudio del proceso de enseñanza-aprendizaje. 


\section{Elementos de la didáctica:}

\section{Metodologías docentes}

Las metodologías docentes se podrían definir como las estrategias de enseñanza con base científica que el o la docente propone en su aula para que los estudiantes adquieran determinados aprendizajes. En esta misma línea, una "estrategia de enseñanza" es la pauta de intervención en el aula decidida por el profesor (puede incluir aspectos de la mediación del profesor, la organización del aula, el uso de recursos didácticos, etc.). Además, cualquier estrategia puede englobar "tareas" (cada actividad a realizar en un tiempo y situación determinada), "procedimientos" (una secuencia de tareas) y/o "técnicas" (secuencia ordenada de tareas y/o procedimientos que conducen a unos resultados precisos) (Fortea, 2019).

Cabe mencionar que la mejor metodología es, en realidad, una combinación de metodologías. Asimismo, para seleccionar una u otra metodología se debe conocer previamente sus ventajas e inconvenientes, tener definidas las intenciones educativas y preparar correctamente la pauta de trabajo (Fortea, 2019).

Asimismo, el cambio de estas en el sistema educativo así como la incorporación de estrategias didácticas supone un cambio no solo conceptual, sino que involucraría otros cambios en los alumnos: actitudinal (interés por resolver la tarea, saber que existen discrepancias entre el saber cotidiano y el científico) y en las habilidades de pensamiento (desarrollo de estrategias metacognitivas) (Villaruel, 2015).

En ese sentido, se vienen implementando diferentes metodologías como el aprendizaje orientado por proyectos, aprendizaje basado en el desarrollo de competencias, prácticas de Aprendizaje-Servicio: percepción del alumnado problemas, estudio de caso, aprendizaje colaborativo, entre otros que ponen el énfasis en la resolución de problemas, en el descubrimiento de nuevos aprendizajes, en el establecimiento de nuevas relaciones e interconexiones entre los contenidos, etc.; favoreciendo así el proceso de construcción de conocimientos relevantes, significativos y motivadores para el estudiantado (Redine, 2019).

La implementación de estas diferentes metodologías mediadas por el aprendizaje por descubrimiento, proyectos e investigación, enfocadas al desarrollo de actitudes y 
habilidades científicas en los educandos que incluyen, además de la secuencia lógica del proceso fundamenta el método científico, el desarrollo de la curiosidad, la flexibilidad, trabajo en equipo, persistencia, flexibilidad, respeto a la vida, razonamiento analítico y deductivo y el pensamiento crítico (Prieto y Sánchez, 2019).

Tabla 1. Metodologías docentes en ciencias naturales

\begin{tabular}{|c|c|c|}
\hline Método & Descripción & Finalidad \\
\hline $\begin{array}{l}\text { Lección } \\
\text { magistral }\end{array}$ & $\begin{array}{l}\text { Método expositivo consistente en la } \\
\text { presentación de un tema lógicamente } \\
\text { estructurado con la finalidad de facilitar } \\
\text { información organizada siguiendo criterios } \\
\text { adecuados a la finalidad pretendida. Centrado } \\
\text { fundamentalmente en la exposición verbal por } \\
\text { parte del profesor de los contenidos sobre la } \\
\text { materia objeto de estudio }\end{array}$ & $\begin{array}{l}\text { Transmitir } \\
\text { Conocimientos y } \\
\text { activar procesos } \\
\text { cognitivos en el } \\
\text { estudiante }\end{array}$ \\
\hline $\begin{array}{l}\text { Resolución } \\
\text { de ejercicios } \\
\text { y problemas }\end{array}$ & $\begin{array}{l}\text { Situaciones donde el alumno debe desarrollar e } \\
\text { interpretar soluciones adecuadas a partir de la } \\
\text { aplicación de rutinas, fórmulas, o } \\
\text { procedimientos para transformar la información } \\
\text { propuesta inicialmente. Se suele usar como } \\
\text { complemento a la lección magistral }\end{array}$ & $\begin{array}{l}\text { Ejercitar, ensayar y } \\
\text { poner en práctica } \\
\text { los conocimientos } \\
\text { previos }\end{array}$ \\
\hline $\begin{array}{l}\text { Aprendizaje } \\
\text { basado en } \\
\text { problemas } \\
\text { (ABP) }\end{array}$ & $\begin{array}{l}\text { Método de enseñanza-aprendizaje cuyo punto } \\
\text { de partida es un problema que, diseñado por el } \\
\text { profesor, el estudiante en grupos de trabajo ha } \\
\text { de abordar de forma ordenada y coordinada las } \\
\text { fases que implican la resolución o desarrollo } \\
\text { del trabajo en torno al problema o situación }\end{array}$ & $\begin{array}{l}\text { Desarrollar } \\
\text { aprendizajes } \\
\text { activos a través de } \\
\text { la resolución de } \\
\text { problemas }\end{array}$ \\
\hline $\begin{array}{l}\text { Estudio de } \\
\text { casos }\end{array}$ & $\begin{array}{l}\text { Análisis intensivo y completo de un hecho, } \\
\text { problema o suceso real con la finalidad de } \\
\text { conocerlo, interpretarlo, resolverlo, generar } \\
\text { hipótesis, contrastar datos, reflexionar, } \\
\text { completar conocimientos, diagnosticarlo y, en } \\
\text { ocasiones, entrenarse en los posibles } \\
\text { procedimientos alternativos de solución }\end{array}$ & $\begin{array}{l}\text { Adquisición de } \\
\text { aprendizajes } \\
\text { mediante el análisis } \\
\text { de casos reales o } \\
\text { simulados }\end{array}$ \\
\hline $\begin{array}{l}\text { Aprendizaje } \\
\text { por proyectos }\end{array}$ & $\begin{array}{l}\text { Método de enseñanza-aprendizaje en el que los } \\
\text { estudiantes llevan a cabo la realización de un } \\
\text { proyecto en un tiempo determinado para } \\
\text { resolver un problema o abordar una tarea } \\
\text { mediante la planificación, diseño y realización } \\
\text { de una serie de actividades y todo ello a partir } \\
\text { del desarrollo y aplicación de aprendizajes } \\
\text { adquiridos y del uso efectivo de recursos }\end{array}$ & $\begin{array}{l}\text { Realización de un } \\
\text { proyecto para la } \\
\text { resolución de un } \\
\text { problema, } \\
\text { aplicando } \\
\text { habilidades y } \\
\text { conocimientos } \\
\text { adquiridos }\end{array}$ \\
\hline $\begin{array}{l}\text { Aprendizaje } \\
\text { cooperativo }\end{array}$ & $\begin{array}{l}\text { Enfoque interactivo de organización del trabajo } \\
\text { en el aula en el cual los alumnos son } \\
\text { responsables de su aprendizaje y del de sus }\end{array}$ & $\begin{array}{l}\text { Desarrollar } \\
\text { aprendizajes } \\
\text { activos y }\end{array}$ \\
\hline
\end{tabular}




\begin{tabular}{|l|l|l|}
\hline & $\begin{array}{l}\text { compañeros en una estrategia de } \\
\text { corresponsabilidad para alcanzar metas e } \\
\text { incentivos grupales }\end{array}$ & $\begin{array}{l}\text { significativos de } \\
\text { forma cooperativa }\end{array}$ \\
\hline $\begin{array}{l}\text { Contrato } \\
\text { didáctico }\end{array}$ & $\begin{array}{l}\text { Alumno y profesor de forma explícita } \\
\text { intercambian opiniones, necesidades, proyectos } \\
\text { y deciden en colaboración como llevar a cabo } \\
\text { el proceso de enseñanza-aprendizaje y lo } \\
\text { reflejan oralmente o por escrito. }\end{array}$ & $\begin{array}{l}\text { Desarrollar el } \\
\text { aprendizaje } \\
\text { autónomo }\end{array}$ \\
\hline $\begin{array}{l}\text { Seminario } \\
\text { Clásico }\end{array}$ & $\begin{array}{l}\text { Encuentros semanales de unos pocos } \\
\text { estudiantes (10 o 15) y un profesor que } \\
\text { actúa como experto y animador. } \\
\text { Se compone de 4 partes: lecturas (iniciales } \\
\text { comunes facilitadas por el profesor e } \\
\text { investigación de ampliación a cargo del } \\
\text { estudiante), redacción progresiva de textos } \\
\text { tutorizada por el profesor, y discusión } \\
\text { del seminario tras la lectura de todos los textos } \\
\text { por todos los estudiantes. }\end{array}$ & $\begin{array}{l}\text { El objetivo es } \\
\text { explorar y estudiar } \\
\text { un tema } \\
\text { especializado en } \\
\text { profundidad. }\end{array}$ \\
\hline $\begin{array}{l}\text { Aprendizaje } \\
\text { a través de } \\
\text { aula virtual }\end{array}$ & $\begin{array}{l}\text { Situación de enseñanza-aprendizaje en las que } \\
\text { se usa un ordenador con } \\
\text { conexión a la red como sistema de } \\
\text { comunicación entre profesor-alumno y se } \\
\text { desarrolla un plan de actividades formativas } \\
\text { integradas dentro del currículo }\end{array}$ & $\begin{array}{l}\text { Facilitar el } \\
\text { "aprendizaje } \\
\text { constructivo" }\end{array}$ \\
\hline
\end{tabular}

Fuente: Elaboración propia basada en Fortea (2019).

\section{Estrategias didácticas}

Una estrategia didáctica se concibe como la estructura de actividad en la que se hacen reales los objetivos y contenidos. Esta estructura implica un proceso que nace desde un punto de partida, que son los contenidos de información, puede ser nueva o alguna información previa que las personas participantes ya posean sobre el tema; y de ahí, hasta el punto en que se espera llegar; es decir, hacer real el objetivo (Orellana, 2017).

\section{Estrategias didácticas en las ciencias naturales}

La literatura científica muestra que en los diversos niveles educativos, conforme se va a avanzando, se incrementa sucesivamente también el desinterés por las materias científicas. En otras palabras, los educandos pierden de forma progresiva la curiosidad y la motivación por el aprendizaje de los contenidos trabajados, y se introducen en un proceso pasivo donde prima la desmotivación y el fracaso académico (Ortega-Quevedo y Gil, 2018). 
En relación con las causas del desinterés se observan una serie de dificultades asociadas al proceso de enseñanza-aprendizaje, estas son:

- Las materias de ciencias suelen orientarse a la consecución en masa de una serie de contenidos que no son contextualizados, es decir se relaciona la ciencia como un curso enciclopédico.

- Los alumnos reciben la información como una avalancha de datos que deben memorizar y retener.

- El uso desmedido de los libros de texto, como base y referencia en el proceso de enseñanza.

- El escaso planteamiento práctico de los contenidos y las malas programaciones. Las experiencias prácticas deben estar contextualizadas y los discentes precisan conocer su finalidad y su relación con la teoría.

- La falta de una perspectiva histórica de la ciencia, así como el aislamiento de los contenidos científicos entre las distintas áreas.

- Evaluaciones cuantitativas y exámenes externos, procesos de evaluación dirigidos a calificar el contenido memorizado y no otras formas de aprendizaje.

- Carencias en la formación del profesorado.

Para revertir esta situación, con el tiempo se han gestado y proporcionado al sector educativo una serie de estrategias didácticas orientadas al beneficio del aprendizaje de las ciencias naturales.

Redine (2019) indica que un primer paso para alcanzar dichas finalidades se requiere, entre otras cuestiones, superar las posiciones clásicas centradas en el aula y la actividad del profesorado, para pasar a organizar la enseñanza utilizando métodos que promuevan la actividad del alumno, sea esta individual o en grupo, y que permitan que los alumnos alcancen las competencias que se proponen como metas de aprendizaje, tal y como se ha visto en las diversas metodologías expuestas en la Tabla 1. 
En esa misma línea, se continúa con el trabajo de las metodologías al aplicar de manera específica estrategias didácticas, $\mathrm{y}$, cabe mencionar que entre las más aplicadas en ciencias naturales se encuentran:

- Investigación

La implementación del método científico como estrategia didáctica requiere el desarrollo de un conjunto de habilidades lógicas para la organización y sistematización de la información, a partir de la participación activa y directa del estudiante, con orientación del docente. Este promueve la construcción del conocimiento permitiendo al estudiante acercarse a situaciones semejantes a las que debe resolver un científico, pero desde su propio entorno, favoreciendo el desarrollo de habilidades cognitivas, actitudinales y de comunicación fomentando principalmente la curiosidad a través procesos investigativos que involucran la observación, formulación de hipótesis, experimentación, verificación de las hipótesis y comparación (Albán, 2010 citado en Prieto y Sánchez, 2019).

- Descubrimiento

Involucra la simulación de fenómenos naturales al controlar variables, realizar comparación y análisis de sus efectos. Este puede ser guiado o autónomo de acuerdo con las pautas dadas por el docente y tiene como propósito que el estudiante busque por sí mismo a las respuestas a los cuestionamientos planteados o construya sus propias conclusiones (González, 2009; Ruiz, 2007 citados en Prieto y Sánchez, 2019).

\section{- Proyectos}

Un proyecto requiere el desarrollo de un conjunto de actividades para alcanzar un objetivo propuesto que, desde el punto de vista didáctico, se extiende más allá del conocimiento tradicional, abarcado acciones que involucren, a través de la práctica, el acercamiento a situaciones novedosas para el estudiante a partir del problema planteado. Esta estrategia les permite a los estudiantes aprender a manejar y utilizar los recursos de los que disponen, desarrollar diferentes técnicas de trabajo teórico y práctico, la organización de un cronograma, favoreciendo el desarrollo de habilidades académicas, sociales y personales mediante el trabajo escolar (Ruiz, 2007 citado en Prieto y Sánchez, 2019). 
Finalmente, Orellana (2017) también indicó que no basta con la elección fortuita de la estrategia, sino que es igualmente trascendental el diseño de esta, donde se debe incluir acciones, actividades y tareas que faciliten llevar a cabo el desarrollo de la estrategia en sí y, para ello, se deben considerar el contenido, la metodología y los logros, aspectos que se describen a continuación:

- El contenido de información: es el criterio específico de una temática que, por la naturaleza de ser aspectos concretos, permite poder tener claro ¿qué es lo que se quiere trasmitir?

- La metodología: es la que describe los pasos por seguir, indicando el ¿cómo trasmitir el contenido? Aquí, se diseña el plan de acción que se debe realizar para poder lograr que la persona usuaria, pase del conocimiento que tiene, hacia un nuevo conocimiento; es decir, permite ver el cómo se debe ir desarrollando las diferentes acciones del plan.

- El logro: este se refiere a lo que se espera, responde a la pregunta ¿para qué se trasmite ese contenido?, su principal característica es que define el propósito que se busca al trabajar esa información o temática.

\section{Didáctica de enseñanza en la Biología Celular}

De manera específica, los estudios acerca del aprendizaje del concepto de célula demuestran la necesidad de: 1. Buscar e implementar estrategias didácticas que promuevan un aprendizaje significativo de célula, 2. Reflexionar y problematizar sobre distintos aspectos que van desde la idoneidad del contenido seleccionado, las estrategias y herramientas de enseñanza utilizadas, 3. Estudiar las estrategias de aprendizaje utilizadas por los estudiantes y la transferencia de conocimiento científico aprendido a situaciones nuevas de aprendizaje, entre otros aspectos.

En ese sentido, cabe mencionar que existe una diversidad de formatos disponibles con distintas aplicaciones didácticas, que facilitan los procesos de enseñanza y aprendizaje. (Gómez et al, 2019). 


\section{Recursos didácticos en la Biología celular}

Lucumí (2015) enfatiza aún más detalladamente en dichas estrategias didácticas a emplear, ya no solo tomando en consideración que se trata de ciencias como materia sino específicamente en biología celular como contenido; en ese sentido, señala que se debe tener en cuenta para su elección y puesta en marcha factores como:

- La caracterización de los contenidos a abordar, justificando su origen, la naturaleza de los problemas que resuelven, las propiedades y las relaciones entre ellos y con otras disciplinas.

- Abordajes múltiples, diversos enfoques y miradas alternativas para una misma situación, que faciliten "ver" la funcionalidad de los distintos contenidos.

- Uso de técnicas de demostración, comprobación y validación.

- Plantear, solucionar y formular problemas adecuados a esta etapa y a las distintas modalidades, educando la razón y a la vez nutriendo la imaginación

- Construir situaciones de aprendizaje que impliquen producciones interesantes (trabajos de investigación, proyectos, acciones comunitarias, etc.) de los alumnos en los que se puedan imbricar sus propios intereses, la realidad actual y las cuestiones que se traten en otros espacios curriculares.

\section{Recursos para el desarrollo de estrategias didácticas en biología celular}

Lucumí (2015) enlista una serie de recursos empleados en las estrategias didácticas del tema en particular:

\section{Lenguaje: Metáforas}

Las metáforas y las analogías son de uso común en bioquímica y biología celular, debido a que estas facilitan la "visualización" de conceptos y procesos relevantes. Por ejemplo las mitocondrias son descritas como plantas de poder para la célula. Otra estrategia es describir los procesos en términos de características humanas (antropomorfismos) o comportamiento intencional, por ejemplo para explicar que la acción de los anticuerpos es atacar o invadir. 


\section{Imágenes}

Las imágenes juegan un papel crítico como herramientas conceptuales en la enseñanza y la investigación, transformando así la forma en que pensamos los fenómenos de la bioquímica y la biología celular.

La importancia de las imágenes es evidente en la comunicación de resultados de investigación y en libros de texto de bioquímica y biología molecular. Los libros son ricos en ilustraciones y con frecuencia incluyen suplementos de gráficos en forma de sitios web y software educativo. Por ejemplo, imágenes que ocupan entre el 30-50\% del espacio de la página en la norma bioquímica y genética molecular y libros de texto de bioquímica, biología celular y molecular.

Estas imágenes son fórmulas químicas y mecanismos, salidas instrumentales, esquemas, diagramas, ilustraciones y fotografías, así como los modelos interactivos y animaciones.

\section{TICs}

Los medios didácticos y recursos basados en las tecnologías de la información y la comunicación (TIC) constituyen un aliado en los procesos de innovación docente como se ha constatado en numerosas investigaciones (Gómez et al, 2016).

Por ejemplo, Lucumí (2015) enfatiza cómo las computadoras ofrecen una gran cantidad de posibilidades, pero si a ello se le suma que cuenten con Internet, es decir que estén conectadas, esto incrementa grandemente su funcionalidad al posibilitar no sólo procesar información almacenada en soportes físicos en cualquier formato digital, sino también como herramienta para acceder a información, recursos y servicios prestados por computadoras remotas, como sistema de publicación y difusión de la información, como medio de comunicación entre seres humanos.

La fuente anterior también detalla que existen muchas herramientas informáticas y bases de datos en internet que son alimentadas por la biología celular; por citar algunos ejemplos el PDB,Gene Bank, el Swiss Prot, Pymol, etc., componen un abanico de herramientas bioinformáticas. El reto consiste en utilizar estos recursos en el proceso de enseñanza aprendizaje de la bioquímica y la biología molecular para las carreras de salud. 


\section{Conclusiones}

En la sociedad actual, las ciencias juegan un papel trascendental en la formación de ciudadanos, pero sobre todo en los estudiantes quienes están en la etapa de definir su futuro con una carrera universitario por lo que resulta clave que cuenten con una cultura integral y con un pensamiento humanista, científico e innovador, que les permita participar en un mundo cada vez más impregnado de Ciencia y Tecnología, uno en el que ellos mismos puedan contribuir.

Es preciso, entonces, que tengan una educación que les permita aprender los contenidos moleculares y celulares, no solo de forma memorística o teórica como antiguamente se hacía sino contextualizando, aplicando, resolviendo problemas reales, es decir, llevando la teoría a situaciones palpables donde se valore el impacto social de estos contenidos de tal manera que sean profundos y significativos; en esto recae el valor de las estrategias didácticas en la enseñanza de ciencias naturales.

\section{Referencias}

Abreu, Y., Barrera, A., Breijo, T., y Bonilla, I. (2018) El proceso de enseñanza aprendizaje de los Estudios Lingüísticos: su impacto en la motivación hacia el estudio de la lengua. MENDIVE Vol. 16 No. 4, pp. 610-623.

Albán, S. (2010). Metodologías didácticas aplicadas por los docentes en las ciencias naturales para el desarrollo de destrezas básicas. Universidad Tecnológica Equinoccial, Ecuador.

Basulto, G., Hechavarria, R. y Mustelier, L. (2020) El enfoque sociocultural-profesional de las ciencias. Experiencias en la disciplina Biología Molecular y Celular. Roca. Revista Científico - Educacional De La Provincia Granma, 16, 1341-1355. https://revistas.udg.co.cu/index.php/roca/article/view/2054

Fortea, M. (2019) Metodologías didácticas para la enseñanza/aprendizaje de competencias $\left(2^{\circ}\right.$ ed.) Colección Materiales para la Docencia Universitaria (MDU) $\mathrm{N}^{\mathrm{o}}$ 1. http://dx.doi.org/10.6035/MDU1

Gómez, E., Cacheiro, M., Camili, C. y Fuentes, J. (2016) Didáctica general y formación del profesorado. España: Universidad Internacional de La Rioja. 
https://www.unir.net/wpcontent/uploads/2016/07/DIDACTICA_GENERAL_baja.pdf

Gómez, S., Chediack, J., Fernández, G., Jerez, M. y Pérez, J. (2019) Disponibilidad de recursos abiertos para la enseñanza y aprendizaje de la biología celular a nivel universitario.

Docentes Conectados

$D C$,

$\mathrm{N}^{\circ} 4$ http://www.evirtual.unsl.edu.ar/revistas/index.php/dc/issue/view/6

González, D. (2009). El método experimental en las clases de Ciencias Naturales. Su utilidad en la Escuela Especial. Material de apoyo a la docencia.

Lucumí, A. (2015) A de la biología molecular y la bioquímica en las carreras del área de la salud retos en la enseñanza de la biología molecular y la bioquímica en las carreras del área de la salud. Boletín virtual, Vol. 4(9), 27-39.

Orellana, C. (2017) La estrategia didáctica y su uso dentro del proceso de enseñanza y aprendizaje en el contexto de las bibliotecas escolares. e-Ciencias de la Información, 7(1), 2-22. https://www.scielo.sa.cr/pdf/eci/v7n1/1659-4142-eci-701-00134.pdf

Ortega-Quevedo, V. y Gil, C. (2018). Estudio de aplicación de modelos didácticos de Ciencias Experimentales en un proyecto Comunidad de Aprendizaje. ReiDoCrea, 8, 80-94. https://www.ugr.es/ reidocrea/8-8.pdf

Pérez, A. (2019) La enseñanza de la lengua portuguesa en la formación superior. Universidad de La Habana. Cuba.

Prieto, G. y Sánchez, A. (2019) La didáctica como disciplina científica y pedagógica. Rastros y Rostros del Saber: Gaceta Académica de la Licenciatura en Educación Básica, Vol. 2, 42-52.

Redine (2019) Estrategias y metodologías didácticas: perspectivas actuales. Eindhoven, NL: Adaya $\quad$ Press. http://www.adayapress.com/wpcontent/uploads/2019/05/Estrategias.pdf

Ruiz, F. (2007). Modelos didácticos para la Enseñanza de las Ciencias Naturales. Revista latinoamericana de estudios en educación, 3 (2), 41 - 60. http://latinoamericana.ucaldas.edu.co/downloads/Latinoamericana3-2_4.pdf 
Villaruel, M. (2015) Modelos educativos: Didáctica para la enseñanza de las ciencias. REDHECS Revista Electrónica de Humanidades, Educación y Comunicación Social, 294-314. 